\title{
DESIGN E PRODUÇÃO DE PROTÓTIPO DE MOBILIÁRIO PÚBLICO A PARTIR DA ANÁLISE DE DEMANDA DOS USUÁRIOS
}

Tomás Queiroz Ferreira Barata

Universidade Estadual "Júlio de Mesquita Filho" - UNESP, Campus Bauru.

barata@faac.unesp.br

Isabella Martino Matos

Universidade Estadual "Júlio de Mesquita Filho" - UNESP, Campus Bauru.

isabella_martino@hotmail.com

Resumo: Este artigo apresenta o processo de projeto e a produção de protótipo de mobiliário público em escala reduzida enfatizando a análise da demanda e o desenvolvimento do design centrado no usuário. A metodologia aplicada no estudo dividiu-se em: a) análise do perfil dos usuários; b) qualificação do espaço público; c) realização de dinâmicas com os usuários; d) atividade projetiva considerando definição de diretrizes, geração e seleção de alternativas e modelagem paramétrica e; e) produção de protótipo em escala reduzida. Os resultados apresentados são informações sobre o perfil dos usuários, dados sobre a qualificação do ambiente, resultados de dinâmicas com os usuários e o registro do processo de projeto e produção do protótipo de mobiliário público.

Palavras-chave: mobiliário, espaços públicos, design centrado no usuário,design participativo.

Abstract:This article presents the process of the project and the production of the public furniture prototype on scale emphasing the analysis of demand and the development of user-centered design. The methodology applied in the study was divided in: a) analysis of the users profile; $b$ ) qualification of the public space; c) performing dynamic with users; d) projective activity considering the definition of guidelines, generation and selection of alternatives and parametric modeling and; e) production of prototype on reduced scale. The presented results are information about the users profile, data about the qualification of the environment, results of the dynamic with users and the registration of the project process and production of the public furniture prototype.

Key-words: furniture, public spaces, user centered design, participatory design 


\section{INTRODUÇÃO}

A atividade do designer deve estar em constante diálogo com o usuário, visto que produtos e serviços necessitam adequar-seà cultura e ao comportamento das pessoas. Moraes (2010) atenta para as consequências e vestígios que o produto deixa nos usuários), apontando que o sentido do design engloba também esses efeitos,e não somente a esfera material e produtiva do artefato.Ainda segundo o autor, a metodologia do ato de projetar deve repensar seu papel específico, transformando-se em um processo maleável, tendo em vista que as formas e modos de produção atuais são mais heterogêneos e transversais.

Considerando que os espaços públicos são as áreas comuns dos indivíduos em uma cidade, o ato de projetar praças, parques e os seus respectivos equipamentos, deve levar em conta toda a dinâmica de uma cidade e a vida cotidiana das pessoas. 0 uso dos espaços públicos se dá quando esses ambientes de fato refletem as necessidades e anseios dos seus usuários (GATTI, 2013). Gatti também salienta que o processo participativo dos habitantesantes do início daatividade projetiva é fundamental para que o projeto do espaço atenda efetivamente às demandas locais e de fato seja apropriado pela população. Esses espaços públicos são compostos de diversos elementos que podem dar forma ao ambiente. Neste estudo, será abordado o mobiliário público como um desses elementos que dá forma e uso ao espaço, ressaltando uma forma projetiva integradora que tem como prioridade a demanda real dos usuários. Afinal, além de promover o conforto dos usuários, os espaços podem sinalizar uma identidade através do mobiliário que merece um projeto específico e detalhado quando projetados para lugares determinados (GATTI, 2013).

A partir dos conceitos expostos acima, tem-se como objeto de estudoo espaço da Central de Laboratórios da Faculdade de Arquitetura, Artes e Comunicação da UNESP, campus de Bauru, este estudo apresenta o processo de desenvolvimento do projeto e a produção de protótipo de mobiliário público com ênfase no design centrado no usuário.

\section{MATERIAIS E MÉTODOS}

As etapas da metodologia e o desenvolvimento de projeto estão apresentados na figura 1.As etapas foram divididas em: a) análise do perfil dos usuários; b)avaliação da qualidade do espaço; c) realização de dinâmicas de configurações e usos do local; d) definição de diretrizes de projeto; e) geração e seleção de alternativas; f) modelagem virtual e; g) produção e modelo em escala reduzida.

Para compreender melhor o usuário, foram mescladas uma abordagem sistêmica e uma abordagem interpessoal. A partir disso foram aplicados questionários e dinâmicas. Osquestionários elaborados foram separados em duas partes: a primeira com o intuito de conhecer o perfil dos usuários, seus hábitos e anseios, e a segunda com o intuito de entender como os usuários qualificam o ambiente. Esses questionários foram aplicados em 42 usuários.

Na primeira parte foram analisadas a faixa etária dos usuários, as atividades desenvolvidas no local, as atividades que os usuários desejariam desenvolver no espaço, a quantidade de dias por semana em que o frequentam e a quantidade de horas em que permanecem no mesmo.

A segunda partedo questionário pretendia entender como os usuários classificavam o ambiente. Essa etapa foi baseada no método diferencial semântico 
(DS), descrito por Osgood (1957) no qual dois pares de conceitos antagônicos são separados por uma escala numérica, na qual o usuário deve escolher um número de maneira a assimilar conceitos que devem ser melhorados ou conservados.

A partir dos dados obtidos com os questionários e dinâmicas, foram definidas diretrizes de projeto, e então foram geradas alternativas a partir de sketches manuais. Após a definição do desenho do mobiliário, foi efetuada uma modelagem virtual e afim de verificar a construtibilidade da peça, foi feito um modelo em escala 1:5.

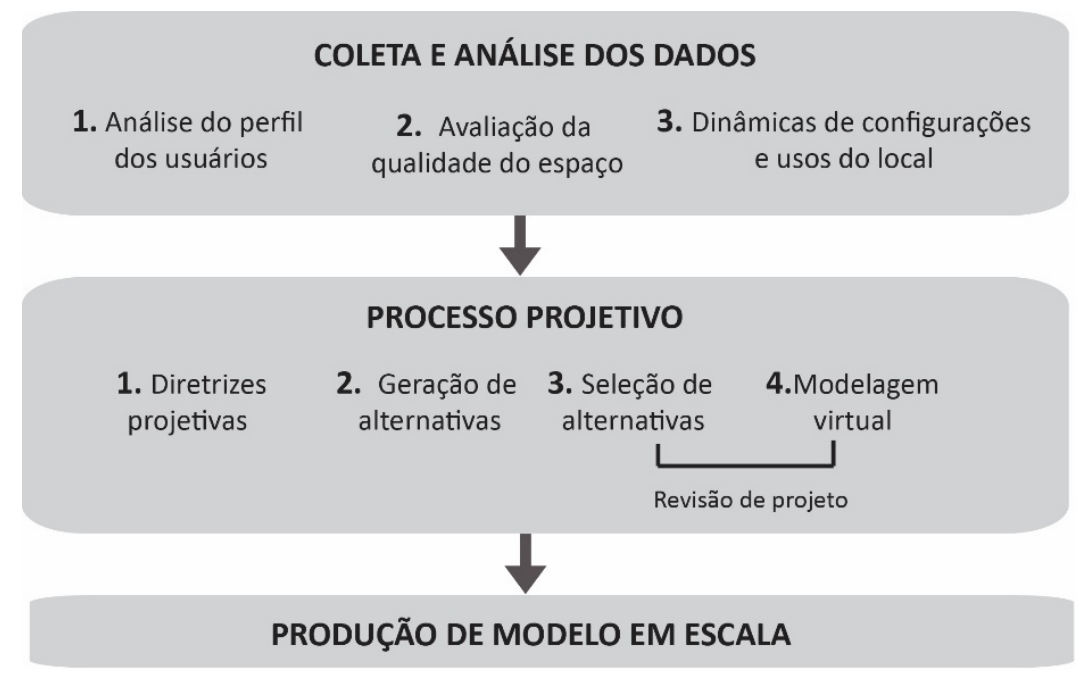

Figura 1: Fluxograma empregado na metodologia da pesquisa Fonte: elaborado pelo autor.

\section{RESULTADOS E DISCUSSÕES}

Os resultados e discussões estão divididos em análise do perfil do usuários, análise da qualificação do ambiente, aplicação de dinâmicas, diretrizes projetivas para o desenvolvimento do protótipo, geração e seleção de alternativas, modelagem virtual e produção do modelo em escala reduzida.

\subsection{Análise do perfil dos usuários}

A análise da demanda dos usuáriosapontou que a faixa etária predominante dos frequentadores do espaço corresponde à 40,5\% e varia entre 21 e 25 anos.A figura 2 apresenta as atividades desenvolvidas no local, e é possível perceber que a maioria dos usuários, 97,6\%, utiliza o local para estudo/trabalho. A segunda atividade mais desenvolvida no local é o descanso, com $31 \%$ de indicação. É necessário perceber que apesar de pouco desenvolvidas, as atividades de confraternização e alimentação são apontadas como desejos dos usuários, como podemos perceber na Figura 3.A figura 4 mostra que a maioria $(33,3 \%)$ dos usuários frequenta o local até 3 vezes por semana,o que representa mais do que a metade dos dias úteis da semana, e $81 \%$ dos usuários frequenta o espaço por mais do que 2 horas como apresentado na Figura 5. Apontando assim que a área não é apenas um local de passagem, e sim um ambiente que deve ser bem estruturado para dar suporte aos seus usuários. 


\section{ATIVIDADES DESENVOLVIDAS NO LOCAL}

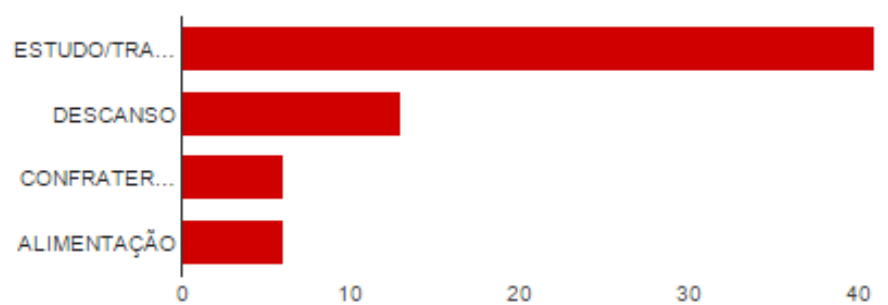

Figura 2: Gráfico das atividades desenvolvidas no local

Fonte: elaborado pelo autor.
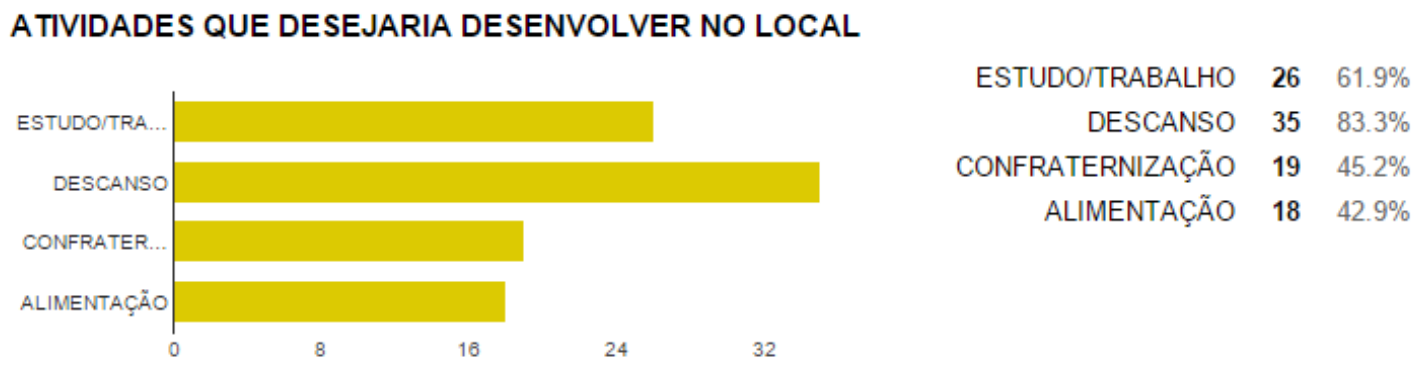

Figura 3: Gráfico das atividades que os usuários desejariam desenvolver Fonte: elaborado pelo autor

QUANTIDADE DE DIAS QUE FREQUENTA O LOCAL:

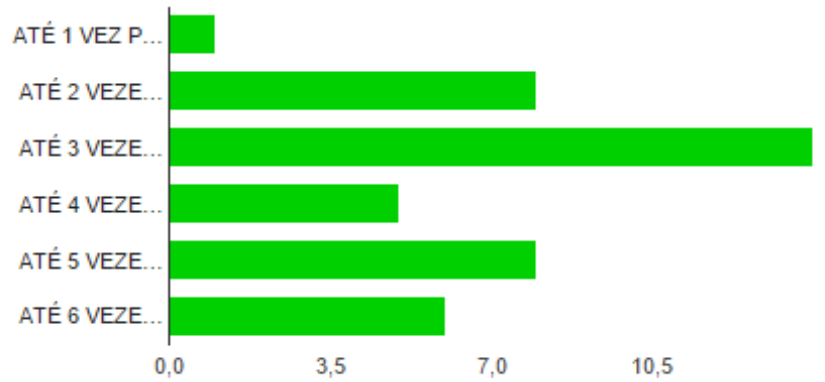

ATÉ 1 VEZ POR SEMANA $\quad 1 \quad 2.4 \%$ ATÉ 2 VEZES POR SEMANA $8 \quad 19 \%$ ATÉ 3 VEZES POR SEMANA $14 \quad 33.3 \%$ ATÉ 4 VEZES POR SEMANA $5 \quad 11.9 \%$ ATÉ 5 VEZES POR SEMANA $\quad \mathbf{8} \quad 19 \%$ ATÉ 6 VEZES POR SEMANA $\quad 6 \quad 14.3 \%$

Figura 4: Gráfico da quantidade de dias em que os usuários frequentam o local Fonte: elaborado pelo autor.

\section{QUANTIDADE DE TEMPO QUE FREQUENTA O LOCAL:}

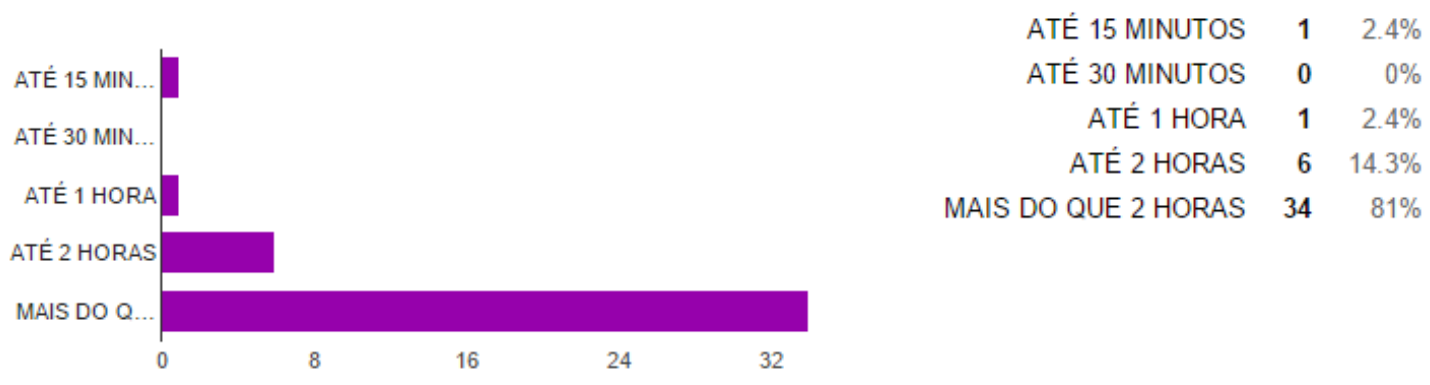

Figura 5. Gráfico da quantidade de tempo em que os usuários frequentam o local Fonte: elaborado pelo autor 


\subsection{Análise da qualificação do ambiente pelos usuários}

Para a parte do questionário que avaliava o local a partir do diferencial semântico (DS) foi necessário estabelecer valores entre os adjetivos apresentados e posteriormente calcular a soma dos valores obtidos. Sendo assim o local foi avaliado como: seguro; desconfortável (Figura 6); pouco iluminado; não atrativo (Figura 7); limpo; pouco mobiliado (Figura 8) e organizado.
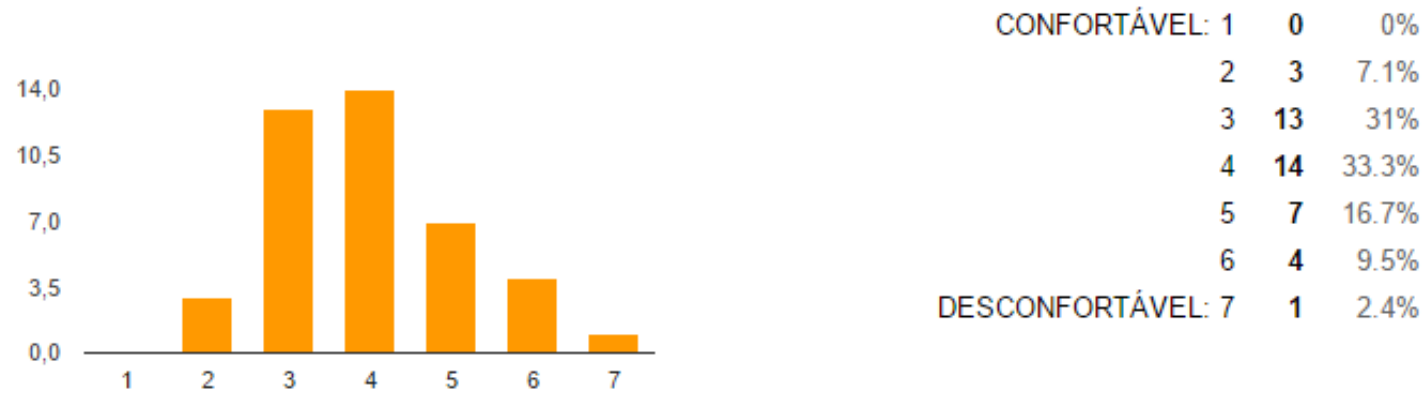

Figura 6: Gráfico da avaliação do par confortável/desconfortável Fonte: elaborado pelo autor
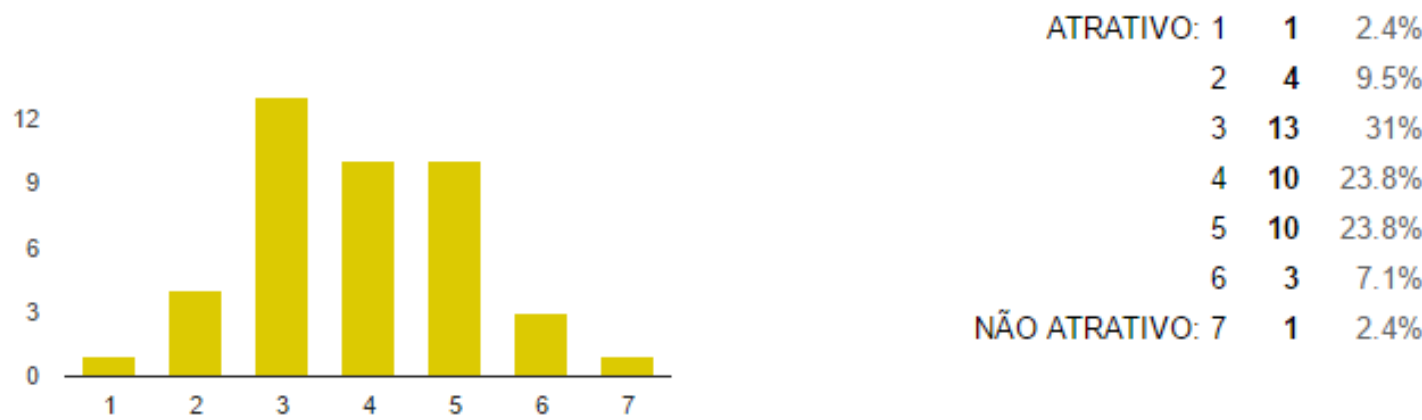

Figura 7: Gráfico da avaliação do par atrativo/não atrativo Fonte: elaborado pelo autor
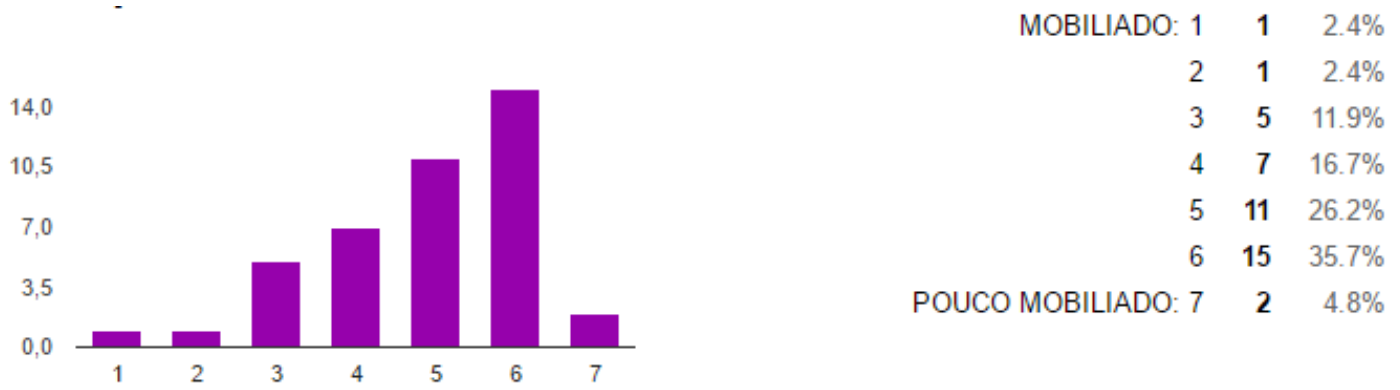

Figura 8: Gráfico da avaliação do par mobiliado/pouco mobiliado Fonte: elaborado pelo autor

\subsection{Aplicação de dinâmicas com os usuários}

A construção da dinâmica teve como intenção compreender como os usuários percebem o espaço e como ele pode se organizar em diferentes configurações dependendo da atividade realizada. A dinâmica foi realizada com 5 grupos de 3 usuários com a faixa etária variando entre 19 e 30 anos, 7 usuários do gênero feminino 8e usuários do gênero masculino. 
Para tanto foi fornecida uma cópia da planta arquitetônica do espaço, bem como as vistas superiores de diferentes tipologias de mobiliário (figura 9), a partir disso os usuários foram orientados a configurar os móveis dentro do espaço de maneira escolher quais e quantos móveis seriam usados em diferentes situações, assim como de que maneira estariam dispostos no espaço.

As diferentes situações, propostas eram: estudo, confraternização e descanso. Os participantes eram instigados a pensar em que tipos de materiais/objetos eram utilizados nas diferentes circunstâncias, bem como com quantos usuários as pessoas costumavam realizar tais atividades, e em que momentos essas atividades aconteciam.

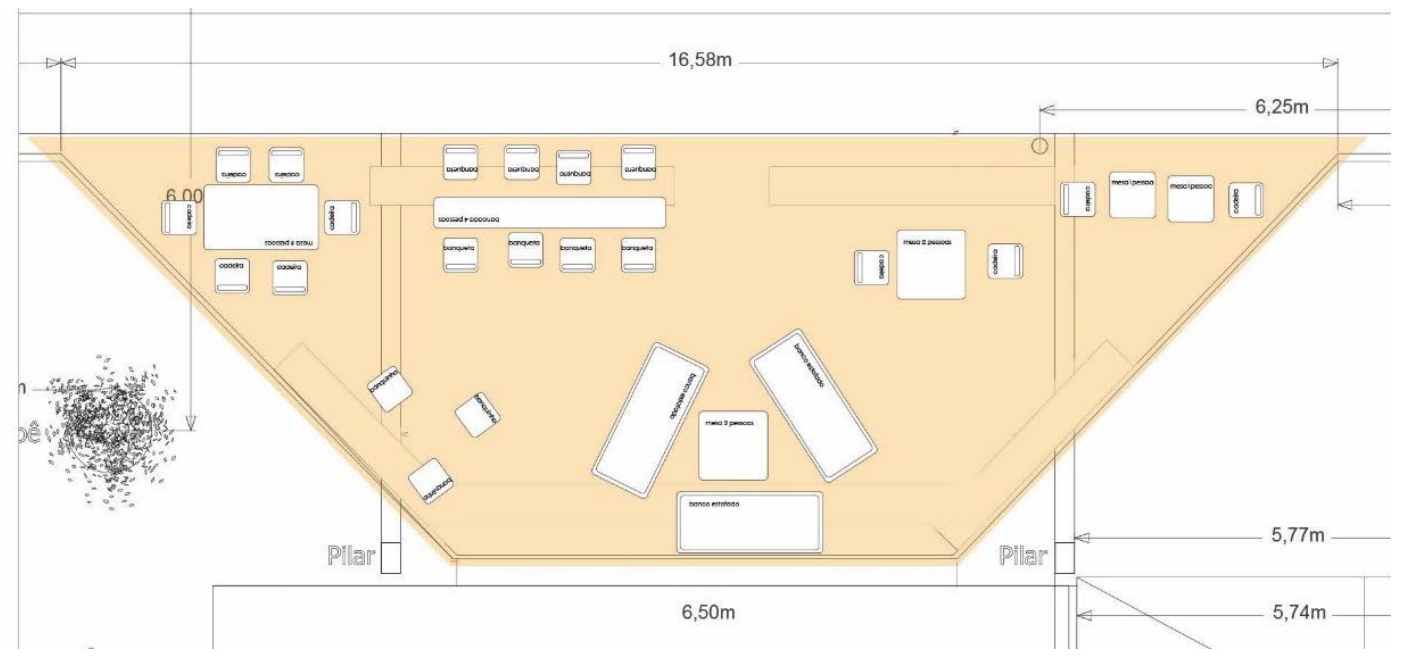

Figura 9: Planta do local com disposição de móveis elaborada durante a dinâmica.

Fonte: elaborado pelo autor

Durante as dinâmicas realizadas foi possível observar que em todas as situações os móveis são diagramados visando mobilidade e adaptabilidade a diferentes situações. Os usuários pontuaram a necessidade de um ambiente que possa ser mutável conforme as diferentes necessidades. Em situações de estudo apontaram que este pode ser desenvolvido tanto em grupo como individualmente, mas que é necessário um grande espaço de mesas e cadeiras para que haja suporte para isso.

No momento de descanso os usuários distribuíram os diferentes mobiliários de maneira reservada e apontaram principalmente para um mobiliário confortável em que se possa dormir e descansar por alguns minutos, todavia apontam momentos de descanso como também momentos de lazer e uso individual de notebook, e para isso salientam a necessidade de um espaço para apoiar o equipamento, bem como para sentar. Para a situação de confraternização as configurações variavam entre muito mobiliário, com a justificativa de que a confraternização deveria abarcar muitos usuários, e poucos mobiliários, com a justificativa de que nessa situação, o ambiente deveria promover principalmente uma mobilidade entre os usuários.

Os mobiliários mais utilizados e pontuados pelos diferentes grupos durante a aplicação das dinâmicas foram bancos estofados econjuntos de bancadas com banquetas. As justificativas da escolha dos mobiliários foram: a) conforto oferecido por um móvel estofado, salientando a não existência desse tipo de mobiliário no campus, apesar da necessidade de descanso; b) flexibilidade que o mobiliário pode promover; além de configurar um espaço individual, principalmente se posicionado às margens 
do ambiente, pode também promover um espaço coletivo, principalmente se posicionado ao centro. Esse conjunto de mobiliário foi relacionado aostipos de moveisexistentes em cafés, os quais muitas vezes são utilizados para trabalhos individuais, contudo dependendo da maneira em que são configurados também podem dar suporte para reuniões dinâmicas.

\subsection{Diretrizes projetivas para o desenvolvimento do protótipo}

Cruzando-se os resultados obtidos na análise do perfil dos usuários, na qualificação do local e na aplicação de dinâmicas e questionários foi possível definir diretrizes de projeto. O mobiliário a ser desenvolvido deveria atender a um público majoritariamente jovem, portanto suas formas poderiam ser mais irreverentes e menos clássicas, além disso, o mobiliário visava atender principalmente a atividade de estudo. O mobiliário deveria ser resistente e confortável, tendo em vista que a maioria dos usuários permanece mais de 2 horas no local, e o frequenta por pelo menos 3 vezes por semana. Além disso, o desenvolvimento da mobília deveria trazer um desenho que contribuísse para tornar o local mais atrativo.

A partir disso, atipologia de mobiliário selecionada para ser desenvolvida foi o conjunto bancada e banqueta. Dentro desse conjunto, a banqueta foi a primeira peça a ser desenvolvida.

\subsection{Geração e seleção de alternativas}

A geração de sketches manuais foi norteada pela união de formas geométricas e formas circulares, de maneira a tentar criar um desenho diferenciado e claro.A figura 10 mostra alguns sketches iniciais.

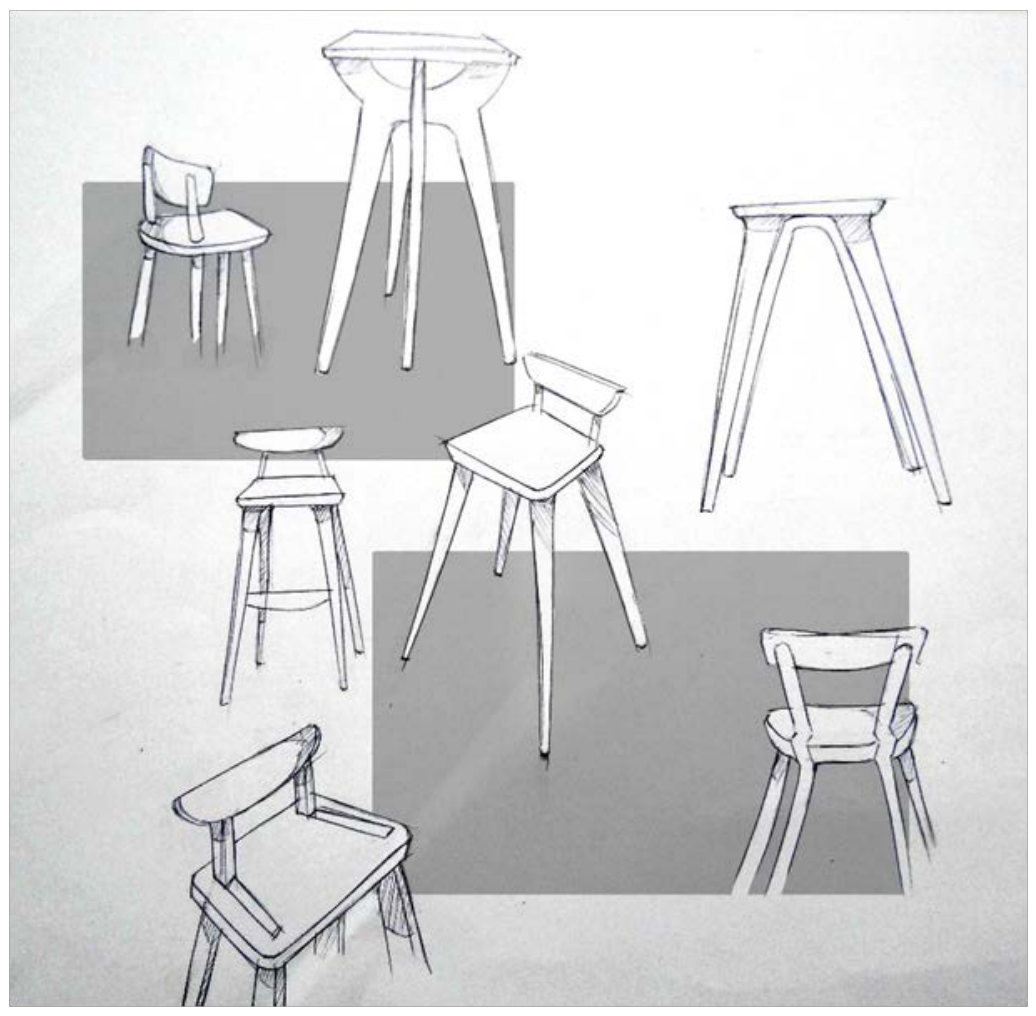

Figura 10: Sketches iniciais para geração de alternativas

Fonte: elaborado pelo autor. 
O sketch final, apresentado na figura 11, tem a junção de curvas suaves, e meio círculos com linhas retas. $O$ desenho criado procurou trazer leveza às formas, além de trabalhar com encaixes de peças para criação de uma estrutura de fixação. A criação da trava nos pés foi pensada essencialmente para que o mobiliário possa ser ergonomicamente confortável para o usuário, além disso, a banqueta também possui encosto possibilitando que o móvel seja utilizado durante mais tempo sem que o usuário se sinta desconfortável.

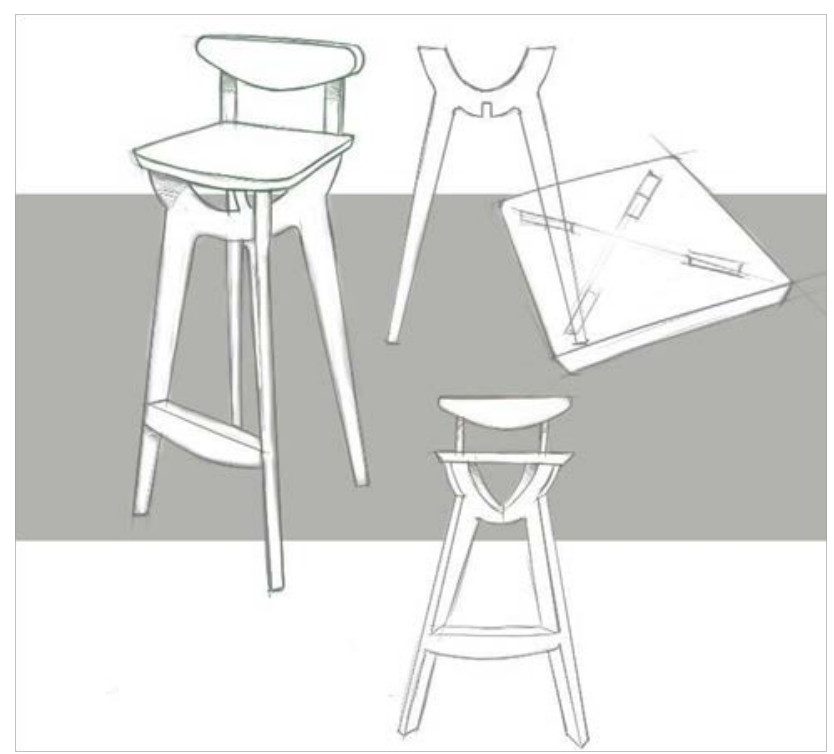

Figura 11: Sketch Final da alternativa selecionada

Fonte: elaborado pelo autor.

\subsection{Modelagem Virtual}

A partir da definição do desenho através dos sketches, foi elaborada uma modelagem virtual utilizando-se o software Solidworks 2013. Durante esse processo foram detalhadas medidas, proporções, formas de encaixe e montagem. Houve também uma revisão de projeto. A modelagem virtual serviu também para simulação de materiais e aprimoramento da forma dos sketches.

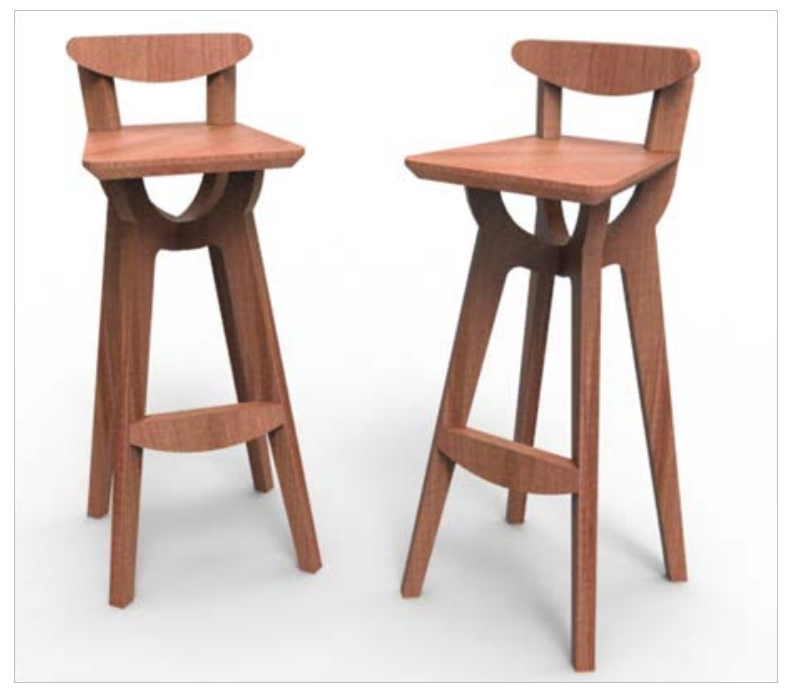

Figura 12: Modelagem virtual

Fonte: elaborado pelo autor 


\subsection{Produção do modelo em escala reduzida}

O modelo em escala foi produzido na escala 1:5 com uma chapa de compensado. Suas peças apresentadas na figura 13aforam feitas simulando a produção em escala real, que seria realizada em um pranchão de madeira de aproximadamente 3 metros de comprimento, $30,0 \mathrm{~cm}$ de largura3,0 cm de espessura, simulado na figura $13 \mathrm{~b}$. A figura $13 \mathrm{c}$ apresenta parte da produção, que envolveu corte em serra de fita, corte delicado com retífica, lixamento, colagem e montagem final apresentada na figura 14 .
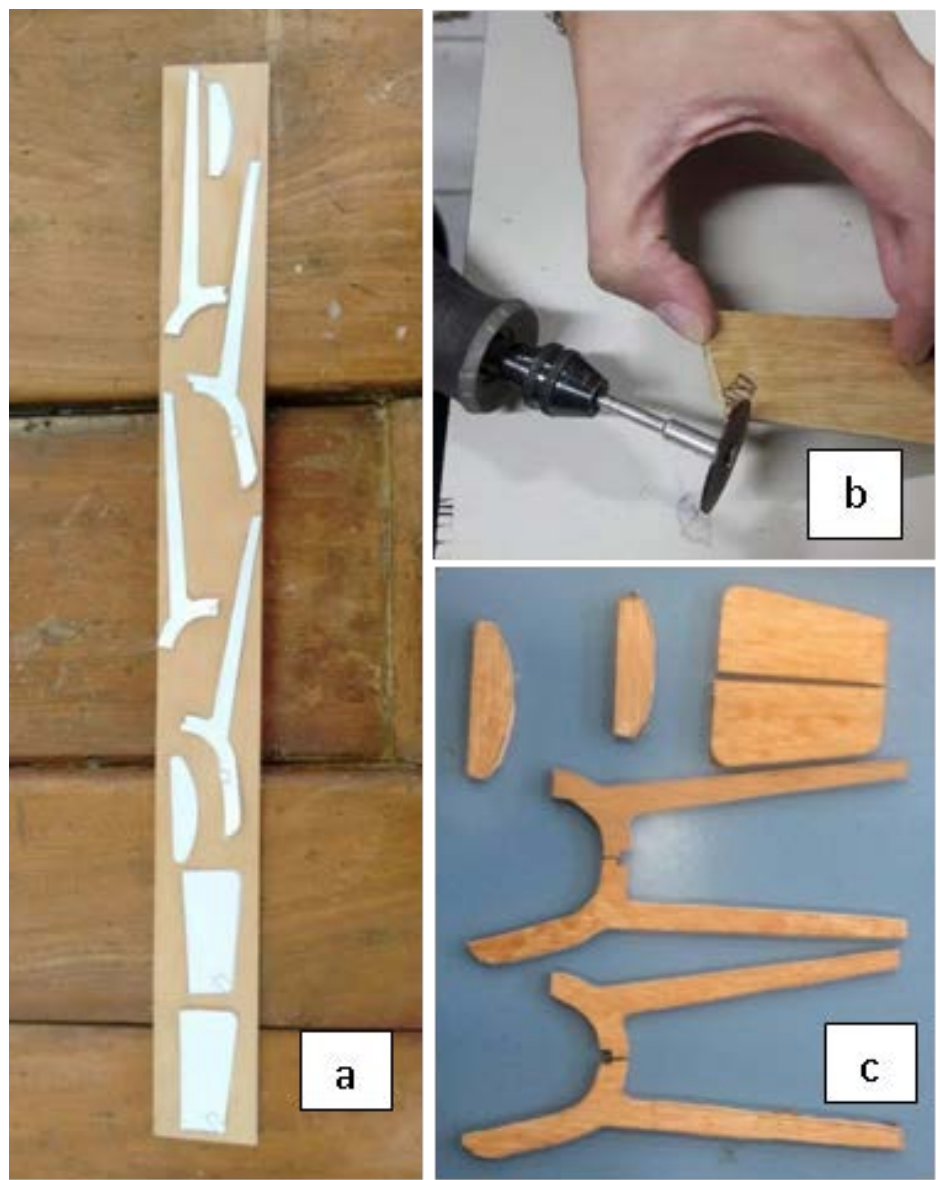

Figura 13: Peças do modelo (a); simulação de peças no pranchão (b) e corte de peças com retífica (c).Fonte: elaborado pelo autor.

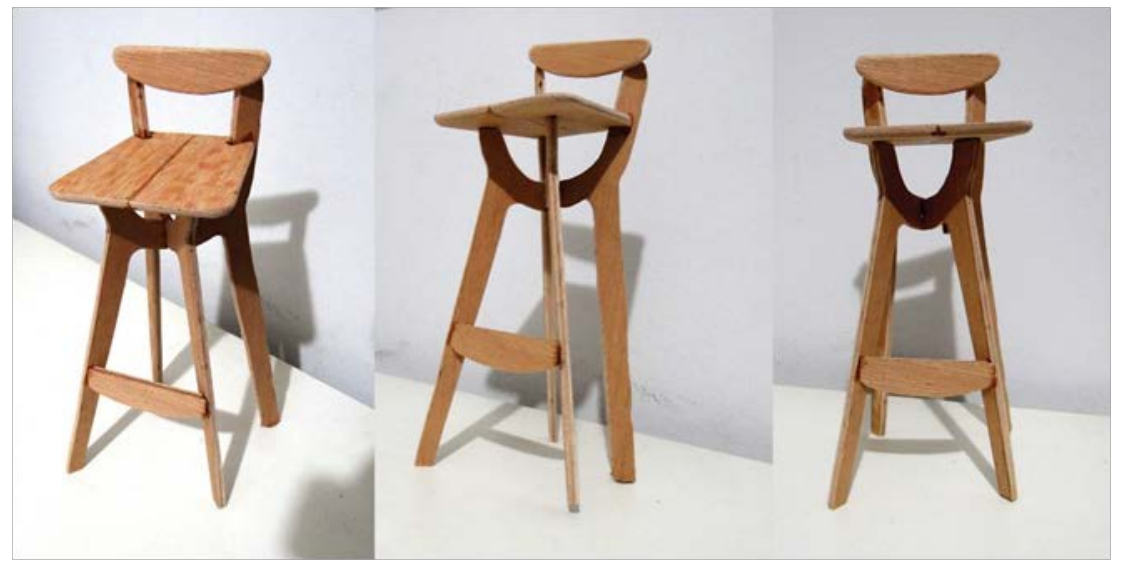

Figura 14: Imagens do protótipo em escala reduzida finalizado

Fonte: elaborado pelo autor 


\section{CONSIDERAÇÕES FINAIS}

Na pesquisa e projeto realizado é possível destacar como consideração geralum resultado coerente a partir da metodologia proposta, que pretendia o envolvimento do usuário no ato de projetar.

Como considerações específicas podemos destacar uma demanda por espaços de permanência estudantil no campus, ambientes atrativos, de qualidade e com mobiliário adequado. É possível destacar também, a aplicação da dinâmica como elemento produtivo para o processo projetivo, fundamental para a escolha do mobiliário a ser desenvolvido. Podemos constatar que a dinâmica também possibilitou uma melhor percepção do ambiente e de suas potencialidades pelos usuários. A dinâmica pode promover, a partir das situações propostas, que o usuário se imaginasse em diversas situações nesse mesmo espaço, muitas vezes julgado como um espaço só para passagem. Como consideração específica é possível destacar também o estabelecimento de diretrizes de projeto como etapa essencial para delimitação das intenções do projeto a partir dos dados adquiridos. Por fim, constatamos que o uso de modelos em escala reduzida contribuiu para a visualização prévia do projeto, possibilitando alterações e aprimoramentos no projeto executivo do mobiliário.

\section{REFERÊNCIAS}

GATTI, Simone. Espaços Públicos: Diagnóstico e metodologia de projeto. São Paulo: ABCP, 2013.

MORAES, Dijon de. Metaprojeto: o design do design. São Paulo: Blucher, 2010.

OSGOOD, Charles E;SUCl, George J; Tannenbaum, Percy.The Measurement of

Meaning. Illinois: University of Illinois, 1957. 